\title{
Abnormalities of middle longitudinal fascicle and disorganization in patients with schizophrenia
}

\section{Citation}

Asami T, Saito Y, Whitford TJ, Makris N, Niznikiewicz M, McCarley RW, Shenton ME, Kubicki M. 2013. Abnormalities of middle longitudinal fascicle and disorganization in patients with schizophrenia. Schizophr Res 143, no. 2-3:253-9. doi:10.1016/j.schres.2012.11.030

\section{Published Version}

doi:10.1016/j.schres.2012.11.030

\section{Permanent link}

http://nrs.harvard.edu/urn-3:HUL.InstRepos:28548724

\section{Terms of Use}

This article was downloaded from Harvard University's DASH repository, and is made available under the terms and conditions applicable to Other Posted Material, as set forth at http:// nrs.harvard.edu/urn-3:HUL.InstRepos:dash.current.terms-of-use\#LAA

\section{Share Your Story}

The Harvard community has made this article openly available.

Please share how this access benefits you. Submit a story.

\section{Accessibility}




\title{
Abnormalities of Middle Longitudinal Fascicle and Disorganization in Patients with Schizophrenia
}

\author{
Takeshi Asami, MD, PhD ${ }^{1,2}$, Yukiko Saito, MD, PhD², Thomas J. Whitford, PhD ${ }^{2,3}$, Nikos \\ Makris, PhD ${ }^{4,5}$, Margaret Niznikiewicz, PhD ${ }^{1}$, Robert W. McCarley, MD ${ }^{1}$, Martha E. Shenton, \\ $\mathbf{P h D}^{1,2,6}$, and Marek Kubicki, MD, PhD ${ }^{\star}, 1,2,6$ \\ ${ }^{1}$ Laboratory of Neuroscience, Clinical Neuroscience Division, Department of Psychiatry, Boston \\ Veterans Affairs Healthcare System, Brockton Division, Harvard Medical School, Brockton, \\ Massachusetts, USA
}

2Psychiatry Neuroimaging Laboratory, Department of Psychiatry, Brigham and Women's Hospital, Harvard Medical School, Boston, Massachusetts, USA

${ }^{3}$ School of Psychology, University of New South Wales, Sydney, New South Wales, Australia

${ }^{4}$ Center for Morphometric Analysis, Athinoula A. Martinos Center for Biomedical Imaging, Departments of Psychiatry, Neurology and Radiology Services, Massachusetts General Hospital, Harvard Medical School, Boston, Massachusetts, USA

${ }^{5}$ Department of Anatomy and Neurobiology, Boston University School of Medicine, Boston, Massachusetts, USA

${ }^{6}$ Surgical Planning Laboratory, MRI Division, Department of Radiology, Brigham and Women's Hospital, Harvard Medical School, Boston, Massachusetts, USA

\section{Abstract}

\begin{abstract}
Introduction-The Middle Longitudinal Fascicle (MdLF) is a long association fiber connecting the superior temporal gyrus (STG) and temporal pole with the angular gyrus through the white matter of the STG, structures which are known to play a crucial role in the pathology of schizophrenia. Functions of MdLF are thought to be related to language and thought processing in the left hemisphere, and with attention in the right hemisphere. While deficits of these functions are core clinical features of schizophrenia, no study has investigated structural abnormalities of MdLF in schizophrenia.
\end{abstract}

Method-3T diffusion tensor data was acquired from twenty-six patients with schizophrenia and twenty-five healthy control subjects. Streamline tractography technique was used to extract MdLF.

\footnotetext{
(C) 2012 Elsevier B.V. All rights reserved.

*Author to whom correspondence should be addressed, Psychiatry Neuroimaging Laboratory, Department of Psychiatry, Brigham and Women's Hospital, Harvard Medical School, 1249 Boylston Street, Boston, Massachusetts 02215 TEL: 617-525-6234 FAX: 617-525-6150 kubicki@bwh.harvard.edu.

Conflict of interest All authors declare that they have no competing financial interests.

Publisher's Disclaimer: This is a PDF file of an unedited manuscript that has been accepted for publication. As a service to our customers we are providing this early version of the manuscript. The manuscript will undergo copyediting, typesetting, and review of the resulting proof before it is published in its final citable form. Please note that during the production process errors may be discovered which could affect the content, and all legal disclaimers that apply to the journal pertain.

Contributors Takeshi Asami, Thomas J. Whitford, Nikos Makris, Martha E. Shenton, and Marek Kubicki designed the study and wrote protocol. Takeshi Asami also wrote the first draft of the manuscript. Yukiko Saito evaluated FAs of the MdLF for interrater reliability. Margaret Niznikiewicz and Robert W. McCarley, managed the recruitment and collected clinical information of participants. Marek Kubicki, Martha E. Shenton, Nikos Makris and Thomas J. Whitford supervised the statistical analyses and edited multiple iterations of the manuscript. All authors contributed to and have improved the final manuscript.
} 
Fractional Anisotropy (FA) was compared between two groups. In addition, relationships were investigated between FA in the left MdLF and the Disorganized Thought Factor derived from the Positive and Negative Symptom Scale five factor model, and between FA in the right MdLF and the Poor Attention.

Result-Relative to control subjects, the patients with chronic schizophrenia showed significant mean FA reductions in the bilateral MdLF. The FA of the left MdLF demonstrated a significant negative association with the Disorganized thoughts factor, and the FA of the right MdLF showed a significant negative relationship with the Poor Attention.

Conclusions-This study provides new evidence for structural deficits in the bilateral MdLF in patients with chronic schizophrenia. It further demonstrates contribution of these abnormalities to the core clinical features - especially to disorganization and attention deficit.

\section{Keywords}

schizophrenia; DTI; FA; middle longitudinal fascicle; disorganization; attention deficit

\section{Introduction}

Language dysfunction and disorganized symptoms have been thought to be among the core features of schizophrenia (McCarley et al., 1999). Several white matter studies have focused on the arcuate fasciculus to explain the pathology of the language and thought dysfunctions in patients with schizophrenia (Hubl et al., 2004; Kubicki et al., 2005).

A recent diffusion tensor imaging (DTI) study has reported another important languagerelated major white matter bundle, the middle longitudinal fascicle (MdLF). Makris et al. (2009) have firstly identified the MdLF in human brain as a long association fiber connecting the superior temporal gyrus (STG) and temporal pole with the inferior parietal lobule (specifically the angular gyrus (AG)) through the white matter of the STG (Makris et al., 2009). Recent DTI studies, however, have reported that MdLF connects not only STG and temporal pole with AG, but also the superior parietal lobule and occipital regions (Makris et al., 2012; Wang et al., 2012).

Functions of the MdLF have yet to be definitively ascertained, but have been suggested to be related with language (Makris et al., 2012), as well as high order auditory association, visuospatial attention (Makris et al., 2012), audiovisual integration (Makris et al., 2012; Wang et al., 2012) and auditory spatial information (Wang et al., 2012).

In previous neuroimaging studies of schizophrenia, STG and AG have been often reported to have structural and functional abnormalities compared to healthy control subjects (HC) (Anderson et al., 2002; Whitford et al., 2006). These abnormalities have been also demonstrated to have strong associations with language-related dysfunctions and attention deficits. Namely, the more severe abnormalities in the STG and AG in the left hemisphere were related to the more severe disorganized symptoms (structural MRI (Anderson et al., 2002; Shenton et al., 1992), SPECT (Liddle et al., 1992)), and positive symptoms (structural MRI (Anderson et al., 2002)), particularly delusions (review (Wible et al., 2009b)) and auditory hallucinations (fMRI (Wible et al., 2001)). Those in the right hemisphere showed relationships to attention deficits (structural MRI (Anderson et al., 2002)) in patients with schizophrenia.

In human brain, the STG and AG are well-known as key components of the language system; the STG includes Wernicke's territory and the AG includes Geschwind's territory (Catani et al., 2005). Functions of the left MdLF are therefore thought to be associated with 
language (Makris et al., 2009). Additionally, it is believed that when a person hears narrative words, Wernicke's area matches the sounds to their meaning, and special neurons in Geschwind's territory are thought to assist by combining the many different properties of words (e.g., sound, sight, and meaning) to achieve full comprehension (Carlson, 2003). In contrast, when a person speaks, the process happens in reverse, that is, the correct words are found to match the thought that is to be expressed in Wernicke's area, and then the chosen words are sent to Broca's area via the arcuate fasciculus, or possibly via a more circuitous pathway through Geschwind's territory (Carlson, 2003; Makris and Pandya, 2009). Furthermore, it is considered that both the STG and AG have important roles for comprehension of narrative speech (Karunanayaka et al., 2007; Wilson et al., 2008), verbal memory, and social cognition (Wible et al., 2009b).

According to these previous studies, we decided to investigate the MdLF in patients with schizophrenia. To focus on language related dysfunctions, the subcomponent of the MdLF connecting the STG and temporal pole with AG was selected on purpose, following a description by (Makris et al., 2009).

We speculate that white matter abnormalities would be found in bilateral MdLF in patients with chronic schizophrenia, and also hypothesized that the MdLF in the left hemisphere would be associated with disorganization, and positive symptoms, particularly delusions and hallucinations, and that the MdLF in the right would be associated with attention deficits.

\section{Methods and Materials}

\subsection{Subjects}

Twenty-six male patients with chronic schizophrenia and twenty-five male HC participated in the study. Participants' recruiting and detailed criteria were described in our previous report (Choi et al., 2011). Groups were matched in age, handedness, parental socioeconomic status and premorbid IQ derived from the Wide Range Achievement Test-3 reading scores (Wilkinson, 1993). Clinical symptoms were estimated using the Positive and Negative Symptom Scale (PANSS) (Kay et al., 1987). Twenty-nine out of the fifty-two subjects were used in our previous DTI study (Whitford et al., 2010). Demographic and clinical data are presented in Table 1. This study was approved by the local IRB at both the VA and Brigham and Women's Hospital. Written informed consent was obtained from all subjects prior to study participation.

\subsection{MRI Protocol}

All subjects were scanned on a 3T GE Echospeed system, using an echo planar imaging DTI sequence. A double echo sequence with an 8 Channel coil was used to reduce eddy-current and EPI spatial related distortions. 51 non-colinear diffusion directions $(\mathrm{B}=900)$ and 9 baseline scans $(B=0)$ were acquired with the following scan parameters: TR $17000 \mathrm{~ms}$, TE $78 \mathrm{~ms}$, FOV $24 \mathrm{~cm}, 144 \times 144$ encoding steps, $1.7 \mathrm{~mm}$ slice thickness. 85 axial slices spanning the entire brain were collected for each subject.

\subsection{Tractography of Middle Longitudinal Fascicle and Reliability}

After reconstruction, diffusion-weighted images were transferred to a LINUX workstation, on which Fractional Anisotropy (FA) maps of the diffusion tensor were calculated. In addition, Radial and Axial Diffusivity (believed to be putative measures of myelin and axonal integrity respectively (Song et al., 2003; Song et al., 2002)) were also calculated. Measurements of the MdLF were performed using 3D-slicer (v2.7, www.slicer.org) and diffusion tensor tractography. To extract subcomponent of the MdLF connecting between STG and temporal pole with AG, streamline tractography and a multiple regions of interest 
(ROI) method was applied (Fitzsimmons et al., 2009), following the description in (Makris et al., 2009). Four ROIs that included gray and white matter of the STG, and one ROI that included gray and white matter of the AG (inferior parietal lobule) were drawn on the FA map. For the STG ROIs, we first identified a coronal slice that unambiguously depicted the temporal stem on the FA map (slice1 in Figure 1-A and B). The first ROI was then drawn on a coronal slice four slices posterior from the temporal stem (slice2 in Figure 1-A and B). The other three ROIs were posterior to the first ROI, every fourth coronal slice (slice3-5 in Figure1-A and B). For the AG ROI, we referred to the 3D view of FreeSurfer (http:// surfer.nmr.mgh.harvard.edu/) parcellation, which had been previously registered to the native DTI space. We then chose a coronal slice, in which the most anterior part of ascending posterior segment of superior temporal sulcus appeared, and manually drew the gray and white matter of the AG (slice6 in Figure1-A and B). Tracts were seeded in the STG ROIs, and streamline tractography was performed. Only those fibers that passed through the ROI in AG were included in the analysis (Figure1-C and D). Tract seeds were placed randomly at $1 \times 1 \times 1 \mathrm{~mm}$ grid, and anisotropy threshold was set as 0.15 . Finally, the FA, Radial $((\lambda 2+\lambda 3) / 2)$ and Axial $(\lambda 1)$ Diffusivity were calculated at every voxel in the extracted fibers of the MdLF, and averaged along each tract for each subject.

All manual processes were conducted by the first author (TA) who was blind to subject group. To assess interrater reliability, two raters blind to diagnosis evaluated mean FAs of MdLF from seven randomly selected cases (TA and YS). Intraclass correlation coefficients (Cronbach's alpha) achieved .979 for the left and .967 for the right MdLF.

\subsection{Statistical Analysis}

The statistical analysis was performed using SPSS version18 (www.spss.com). To determine group differences in each DTI measure (mean FA, Radial, and Axial Diffusivity), a repeated-measures analysis of variance (ANOVA) was employed for each DTI measure separately with group as a between-subjects factor and side as a within-subjects factor.

To verify our hypotheses regarding structural-symptomatic relationships in patients with schizophrenia, we first investigated the association between DTI measures of the MdLF in the left hemisphere and the Disorganized thoughts factor (sum of P2, N5, N7, G5, G10, G11, and G15) derived from a PANSS five-factor model (Emsley et al., 2007; Emsley et al., 2003), Delusions (P1), and Hallucinatory behavior (P3). Secondly, we evaluated the relationship between integrity of the MdLF in the right hemisphere and Poor Attention (G11). Spearman's correlation analysis was used and significant levels were set $P<.05$ because of the hypothesis driven correlation analyses. In addition, relationships between FA of the MdLF and age and duration of illness were evaluated.

\section{Results}

\subsection{Group differences in DTI measures of Middle Longitudinal Fascicle}

The repeated measures ANOVA revealed significant group effects in the FA of the MdLF ( $F$ $(1,49)=6.886, \mathrm{p}=.012)$. Although there was no side-by-group interaction $(F(1,49)=.108, \mathrm{p}=$. 744 ), we decided to conduct post-hoc two sample $t$-tests for each side separately to investigate any differences within hemispheres. The t-tests showed significant mean FA reductions in both left and right MdLFs in patients with schizophrenia compared with HC (mean FA \pm SD, left; schizophrenia: $0.41 \pm 0.02$, HC: $0.43 \pm 0.03$, $\mathrm{t}=2.36, \mathrm{p}=.022$, right: schizophrenia: $0.42 \pm 0.02, \mathrm{HC}: 0.43 \pm 0.03, \mathrm{t}=2.10, \mathrm{p}=.041$ ) (Figure 2). The repeated measures ANOVA for Radial Diffusivity also showed significant group effects $(F$ $(1,49)=4.452, \mathrm{p}=.040)$ and no side-by-group interaction $(F(1,49)=.469, \mathrm{p}=.497)$. Post-hoc $t$ tests revealed significant increase of Radial Diffusivity for the right MdLF, and trend level 
increase for the left MdLF in patients with schizophrenia compared with HC (mean Radial Diffusivity \pm SD, left; schizophrenia: $0.69 \pm 0.03$, HC: $0.67 \pm 0.04, \mathrm{t}=1.79, \mathrm{p}=.080$, right: schizophrenia: $0.68 \pm 0.03$, HC: $0.66 \pm 0.04, \mathrm{t}=2.16, \mathrm{p}=.036$ ) (Figure 2). There were no group effects $(F(1,49)=.049, \mathrm{p}=.825)$ or side-by-group interaction $(F(1,49)=.746, \mathrm{p}=.392)$ for Axial Diffusivity.

\subsection{Correlation Analysis}

Patients with schizophrenia showed a strong negative correlation between FA of left MdLF and the Disorganized thoughts factor $(\mathrm{rho}=-0.51, \mathrm{p}=.007)$, and also showed a trend for positive association with the Delusions ( $r h o=0.36, p=.074$ ) (Figure 3), but no association with the Hallucinatory behavior ( $\mathrm{rho}=0.10, \mathrm{p}=.635$ ). On the other hand, FA of right MdLF showed a significant negative relationship with the Poor Attention ( $\mathrm{rho}=-0.40, \mathrm{p}=.042)$ (Figure 3). To evaluate side effects, we conducted additional correlation analyses and confirmed no significant relationships between FA of right MdLF and the Disorganized thoughts factor (rho $=-0.28, \mathrm{p}=.171$ ) or the Delusions $(\mathrm{rho}=0.18, \mathrm{p}=.372)$, and between FA of left MdLF and the Poor Attention ( $\mathrm{rho}=-0.33, \mathrm{p}=.106$ ). Medication dosage showed no association with FA for either the left or the right MdLF (left: rho=-0.17, $\mathrm{p}=.402$, right: $\mathrm{rho}=-0.32, \mathrm{p}=.125)$. FA of the MdLF in both hemispheres showed no significant associations with age in either the patient or control groups (schizophrenia, left: rho= $=0.12$, $\mathrm{p}=.571$, right: rho $=-0.27, \mathrm{p}=.189$; control subjects, left: rho $=-0.18, \mathrm{p}=.393$, right: rho= $-0.08, \mathrm{p}=.690)$. FA of the MdLF also had no significant relationship with the duration of illness in the patient group (left: rho=-.04, $\mathrm{p}=.841$, right: $r h o=-0.27, \mathrm{p}=.182$ ).

\section{Discussion}

The current DTI-tractography study provides new evidence that patients with chronic schizophrenia exhibit significant DTI abnormalities in the language-related subcomponent of the MdLF compared to the HC, and that these abnormalities are associated with patients' clinical symptoms. To the best of our knowledge, this is the first study which has investigated the MdLF in schizophrenia.

The group comparisons of the DTI measures in this study revealed that the patients with schizophrenia showed significant FA reductions in the bilateral MdLF, trend-level (left MdLF) and significant (right MdLF) increases in Radial Diffusivity, and no changes in Axial Diffusivity compared to the matched HC. Previous animal studies have indicated that our findings may reflect myelin abnormalities (myelin loss, degeneration, demyelination) rather than damages of axonal membrane (Song et al., 2003; Song et al., 2002; Song et al., 2005). A recent DTI study from our laboratory has also demonstrated findings of a similar nature in the anterior part of the corpus callosum in patients with chronic schizophrenia compared to HC (Whitford et al., 2010).

In our hypothesis-driven correlation analyses, the structural (myelin) abnormalities in the MdLF were demonstrated to have association with clinical symptoms.

Firstly, our analysis demonstrated the strong negative correlation between FA of the left MdLF and the Disorganized thoughts factor. The Disorganized thoughts factor from the PANSS five factor model has been thought to reflect general thought/cognitive dysfunctions rather than specific thought disorders, because this factor includes subscales related to both positive and negative dimensions of abnormal thinking (Emsley et al., 2003). Disorganized symptoms are among the most characteristic symptoms of schizophrenia (Bleuler, 1911; Hardy-Bayle et al., 2003), and are generally thought to include thought and speech disorders, confusion, loose associations, disorientation, and problems with memory (HardyBayle et al., 2003). Considering that the left MdLF can be involved in such language-related 
processes, comprehension, and auditory verbal memory (Kircher et al., 2007; Makris et al., 2009; Wilson et al., 2008), it is notable that the left - and not the right - MdLF was correlated with patients' disorganization scores. A recent resection study has reported that the left anterior part of the MdLF was not essential for language (De Witt Hamer et al., 2010). Since, however, Wernicke's and Geschwind's territories are connected by posterior part of the MdLF, the structural deficits in the left MdLF can still contribute to language dysfunction such as disorganization. Our findings are consistent with previous studies reporting associations between disorganization scores and glucose metabolism or cerebral blood flow in the left posterior temporal regions (Kaplan et al., 1993; Liddle et al., 1992) and inferior parietal regions (Kaplan et al., 1993). It is unlikely, however, that disorganization symptoms are exclusively caused by deficits in the left MdLF; as previous neuroimaging studies have reported (Goghari et al., 2010; Lahti et al., 2006) that frontal regions, including Broca's area, may also play an important role in the pathology of disorganization observed in schizophrenia.

Secondly, we confirmed that the FA of the left MdLF showed a trend-level positive association with Delusions. Delusions are thought to be a likely result of abnormal reinforcement learning, and/or an imbalance between new evidence and prior beliefs (Corlett et al., 2007; Stephan et al., 2009). Functions of the left STG and AG include comprehension of speech and verbal memory (Wible et al., 2009b; Wilson et al., 2008). Structural disturbances in the left MdLF could therefore provoke abnormal learning and memories, which might result in delusions.

In terms of the right hemisphere, as we hypothesized, patients with schizophrenia demonstrated a negative relationship between FA of the right MdLF and Poor Attention, which evaluated 'failure in focused alertness' (Kay et al., 1987). In humans, it is thought that alertness is subserved mostly by structures in the right hemisphere (Sturm and Willmes, 2001). Indeed, a previous study from our laboratory has reported such a relationship. Here, the lower alertness scores were associated with the smaller volumes of the cingulum bundle in the right hemisphere in patients with chronic schizophrenia (Nestor et al., 2007). Thus, it is of particular note that this study demonstrates an association between attention deficits and structural abnormalities in the right MdLF in patients with schizophrenia.

While the mechanisms underlying the observed DTI-symptomatic relationships are unclear, one of the possible explanations put forward by our group is based on the delayed action potential and asynchronies in certain neural networks in patients with schizophrenia (see (Whitford et al., 2010)). Another, alternative model recently suggested for such anatomyfunction associations, is based on 'activity-dependent neural plasticity'.

More specifically, some DTI studies for HC have demonstrated that FA increased longitudinally after training (Takeuchi et al., 2010), and that the trained brains showed higher FA compared to non-trained brains (Bengtsson et al., 2005). These investigators have also reported that the degree of increase in FA was positively related to longer durations of training (Bengtsson et al., 2005; Fields, 2005). These findings suggest that brain activities can change FAs. Indeed, a previous animal study has shown some pathological evidence for this brain activity-FA relationship that specific frequencies of action potential firing affected myelination (Stevens et al., 1998). Based on these findings, it may be possible that frequent action potential firings introduce neural plasticity (involving myelination) and thus, FA increases may then appear in the white matter.

In schizophrenia, previous functional neuroimaging studies have demonstrated positive associations between abnormal hyperactivation in gray matter and positive symptoms (Shergill et al., 2000; Wible et al., 2009a). Thus, abnormal hyperactivation, in other words, 
the frequent firings of action potential in gray matter regions, may introduce FA increases in the white matter connecting those gray matter regions. This may appear as positive associations between FA and positive symptoms (e.g., delusions). In terms of cognitive dysfunction and negative symptoms, these have been thought to be associated with hypoactivities in certain brain regions (Buchsbaum and Hazlett, 1998; Gur and Gur, 1995). Therefore, a lower frequency of action potential firing may result in decreased FA in white matter connecting these gray matter regions. This may appear as a negative association between FA and cognitive dysfunction including disorganized symptoms, and negative symptoms.

A previous postmortem study has provided some evidence for this model, where it was reported that patients with schizophrenia showed a less clustered arrangement of oligodendrocytes in the frontal lobe precisely where previous functional imaging studies demonstrated hypofrontalities (Buchsbaum and Hazlett, 1998; Gur and Gur, 1995). The less clustered arrangement of oligodendrocytes may reflect abnormal neural plasticity in schizophrenia.

We believe that those two models are not exclusive, and might be used in concert to understand and to describe better interactions between anatomy and function. Finally, while symptoms (brain activities) may affect neural plasticity and FA, white matter integrity and FA are also influenced by genetic effects in schizophrenia (Tkachev et al., 2003), which should be taken into account in future modeling studies.

Limitations. Firstly, tracing of the MdLF in this study was limited to the connection between STG and temporal pole with AG given that, we focused on language-related functions of this fiber bundle. Studies investigating other connections within MdLF will be necessary to uncover more completely the role of this fiber pathway in schizophrenia. Secondly, results of the correlation analysis between FA of the left MdLF and Delusions were significant only at the trend-level. A study with larger sample would be needed to establish this association. Thirdly, all patients were in the chronic stage of illness, and almost all received medication at the time of scan. Studies with medication-naïve patients, such as the DTI study of (Mandl et al., 2012) are needed. Fourthly, FA of the MdLF showed no association with age or duration of illness. Few previous DTI studies have reported linear association between age and FA in several white matter regions (Giorgio et al., 2010). Other studies, however, have suggested that the relationship between FA and age might be non-linear (Lebel and Beaulieu, 2011; Lebel et al., 2010). Larger number of subjects with wider range of age and duration of illness would thus be needed to evaluate those effects. Finally, MdLF should also be investigated in patients with first-episode schizophrenia to uncover when structural abnormalities occur and how these abnormalities contribute to the pathology of schizophrenia.

In conclusion, the current DTI-tractography study provides new evidence that the MdLF plays an important role in the pathology of chronic schizophrenia. FA reductions with increases in Radial Diffusivity and no changes in Axial Diffusivity suggest that myelin abnormalities may contribute significantly to these abnormalities. In addition, the left MdLF demonstrates the relationship with disorganized thoughts, and at the trend-level correlations with delusions, and the right MdLF shows association with poor attention. Language and thought dysfunction have been thought to be associated with abnormalities in perisylvian cortices. It is necessary to consider MdLF, as well as arcuate fascicule, to achieve a more comprehensive understanding of thought dysfunction in patients with chronic schizophrenia. 


\section{Acknowledgments}

This study was supported, in part, by grants from the National Institute of Health (K05 MH070047 and R01 MH 50740 to MES, R01 MH 40799 to RWM, R01MH 074794 to MK, P50MH 080272-CIDAR award- to RWM, MES, MK; R21MH084041, R01DA027804 and ARRA-NIH-NCCAM to NM), the Department of Veterans Affairs Merit Awards (MES, RWM), the VA Schizophrenia Center Grant (RWM/MES/MK). This work is also, in part, supported by the National Alliance for Medical Image Computing (NA-MIC), the latter a grant supported through the National Institutes of Health Roadmap for Medical Research, Grant U54 EB005149 (MK). TJW is supported by an Overseas-Based Biomedical Training Fellowship from the National Health and Medical Research Council of Australia (\#520627), and a Young Investigator Award from the National Alliance for Research on Schizophrenia and Depression (NARSAD).

Role of the Funding Source All of the study sponsors had no further role in study design; in the collection, analysis and interpretation of data; in the writing of the report; and in the decision to submit the paper for publication.

\section{References}

Anderson JE, Wible CG, McCarley RW, Jakab M, Kasai K, Shenton ME. An MRI study of temporal lobe abnormalities and negative symptoms in chronic schizophrenia. Schizophrenia research. 2002; 58(2-3):123-134. [PubMed: 12409152]

Bengtsson SL, Nagy Z, Skare S, Forsman L, Forssberg H, Ullen F. Extensive piano practicing has regionally specific effects on white matter development. Nature neuroscience. 2005; 8(9):11481150 .

Bleuler, E. Dementia Praecox or the Group pf Schizophrenias. International Universities Oress; New York: 1911.

Buchsbaum MS, Hazlett EA. Positron emission tomography studies of abnormal glucose metabolism in schizophrenia. Schizophrenia bulletin. 1998; 24(3):343-364. [PubMed: 9718628]

Carlson, NR. Physiology of Behavior (Japanese language edition). 8th ed. Maruzen Co., Ltd; Tokyo: 2003.

Catani M, Jones DK, ffytche DH. Perisylvian language networks of the human brain. Annals of neurology. 2005; 57(1):8-16. [PubMed: 15597383]

Choi H, Kubicki M, Whitford TJ, Alvarado JL, Terry DP, Niznikiewicz M, McCarley RW, Kwon JS, Shenton ME. Diffusion tensor imaging of anterior commissural fibers in patients with schizophrenia. Schizophrenia research. 2011; 130(1-3):78-85. [PubMed: 21561738]

Corlett PR, Murray GK, Honey GD, Aitken MR, Shanks DR, Robbins TW, Bullmore ET, Dickinson A, Fletcher PC. Disrupted prediction-error signal in psychosis: evidence for an associative account of delusions. Brain. 2007; 130(Pt 9):2387-2400. [PubMed: 17690132]

De Witt Hamer PC, Moritz-Gasser S, Gatignol P, Duffau H. Is the human left middle longitudinal fascicle essential for language? A brain electrostimulation study. Human brain mapping. 2010

Emsley R, Rabinowitz J, Medori R. Remission in early psychosis: Rates, predictors, and clinical and functional outcome correlates. Schizophrenia research. 2007; 89(1-3):129-139. [PubMed: 17095194]

Emsley R, Rabinowitz J, Torreman M. The factor structure for the Positive and Negative Syndrome Scale (PANSS) in recent-onset psychosis. Schizophrenia research. 2003; 61(1):47-57. [PubMed: 12648735]

Fields RD. Myelination: an overlooked mechanism of synaptic plasticity? Neuroscientist. 2005; 11(6): 528-531. [PubMed: 16282593]

Fitzsimmons J, Kubicki M, Smith K, Bushell G, Estepar RS, Westin CF, Nestor PG, Niznikiewicz MA, Kikinis R, McCarley RW, Shenton ME. Diffusion tractography of the fornix in schizophrenia. Schizophrenia research. 2009; 107(1):39-46. [PubMed: 19046624]

Giorgio A, Santelli L, Tomassini V, Bosnell R, Smith S, De Stefano N, Johansen-Berg H. Age-related changes in grey and white matter structure throughout adulthood. NeuroImage. 2010; 51(3):943951. [PubMed: 20211265] 
Goghari VM, Sponheim SR, MacDonald AW 3rd. The functional neuroanatomy of symptom dimensions in schizophrenia: a qualitative and quantitative review of a persistent question. Neuroscience and biobehavioral reviews. 2010; 34(3):468-486. [PubMed: 19772872]

Gur RC, Gur RE. Hypofrontality in schizophrenia: RIP. Lancet. 1995; 345(8962):1383-1384. [PubMed: 7760605]

Hardy-Bayle MC, Sarfati Y, Passerieux C. The cognitive basis of disorganization symptomatology in schizophrenia and its clinical correlates: toward a pathogenetic approach to disorganization. Schizophrenia bulletin. 2003; 29(3):459-471. [PubMed: 14609240]

Hubl D, Koenig T, Strik W, Federspiel A, Kreis R, Boesch C, Maier SE, Schroth G, Lovblad K, Dierks T. Pathways that make voices: white matter changes in auditory hallucinations. Archives of general psychiatry. 2004; 61(7):658-668. [PubMed: 15237078]

Kaplan RD, Szechtman H, Franco S, Szechtman B, Nahmias C, Garnett ES, List S, Cleghorn JM. Three clinical syndromes of schizophrenia in untreated subjects: relation to brain glucose activity measured by positron emission tomography (PET). Schizophrenia research. 1993; 11(1):47-54. [PubMed: 8297804]

Karunanayaka PR, Holland SK, Schmithorst VJ, Solodkin A, Chen EE, Szaflarski JP, Plante E. Agerelated connectivity changes in fMRI data from children listening to stories. NeuroImage. 2007; 34(1):349-360. [PubMed: 17064940]

Kay SR, Fiszbein A, Opler LA. The positive and negative syndrome scale (PANSS) for schizophrenia. Schizophrenia bulletin. 1987; 13(2):261-276. [PubMed: 3616518]

Kircher TT, Leube DT, Erb M, Grodd W, Rapp AM. Neural correlates of metaphor processing in schizophrenia. NeuroImage. 2007; 34(1):281-289. [PubMed: 17081771]

Kubicki M, Park H, Westin CF, Nestor PG, Mulkern RV, Maier SE, Niznikiewicz M, Connor EE, Levitt JJ, Frumin M, Kikinis R, Jolesz FA, McCarley RW, Shenton ME. DTI and MTR abnormalities in schizophrenia: analysis of white matter integrity. NeuroImage. 2005; 26(4):11091118. [PubMed: 15878290]

Lahti AC, Weiler MA, Holcomb HH, Tamminga CA, Carpenter WT, McMahon R. Correlations between $\mathrm{rCBF}$ and symptoms in two independent cohorts of drug-free patients with schizophrenia. Neuropsychopharmacology. 2006; 31(1):221-230. [PubMed: 16123774]

Lebel C, Beaulieu C. Longitudinal development of human brain wiring continues from childhood into adulthood. The Journal of neuroscience : the official journal of the Society for Neuroscience. 2011; 31(30):10937-10947. [PubMed: 21795544]

Lebel C, Caverhill-Godkewitsch S, Beaulieu C. Age-related regional variations of the corpus callosum identified by diffusion tensor tractography. NeuroImage. 2010; 52(1):20-31. [PubMed: 20362683]

Liddle PF, Friston KJ, Frith CD, Hirsch SR, Jones T, Frackowiak RS. Patterns of cerebral blood flow in schizophrenia. Br J Psychiatry. 1992; 160:179-186. [PubMed: 1540757]

Makris N, Pandya DN. The extreme capsule in humans and rethinking of the language circuitry. Brain structure \& function. 2009; 213(3):343-358. [PubMed: 19104833]

Makris N, Papadimitriou GM, Kaiser JR, Sorg S, Kennedy DN, Pandya DN. Delineation of the middle longitudinal fascicle in humans: a quantitative, in vivo, DT-MRI study. Cereb Cortex. 2009; 19(4): 777-785. [PubMed: 18669591]

Makris N, Preti MG, Asami T, Pelavin P, Campbell B, Papadimitriou GM, Kaiser J, Baselli G, Westin $\mathrm{CF}$, Shenton ME, Kubicki M. Human middle longitudinal fascicle: variations in patterns of anatomical connections. Brain structure \& function. 2012

Mandl RC, Rais M, van Baal GC, van Haren NE, Cahn W, Kahn RS, Hulshoff Pol HE. Altered white matter connectivity in never-medicated patients with schizophrenia. Human brain mapping. 2012

McCarley RW, Niznikiewicz MA, Salisbury DF, Nestor PG, O’Donnell BF, Hirayasu Y, Grunze H, Greene RW, Shenton ME. Cognitive dysfunction in schizophrenia: unifying basic research and clinical aspects. European archives of psychiatry and clinical neuroscience. 1999; 249(Suppl 4): 69-82. [PubMed: 10654112]

Nestor PG, Kubicki M, Spencer KM, Niznikiewicz M, McCarley RW, Shenton ME. Attentional networks and cingulum bundle in chronic schizophrenia. Schizophrenia research. 2007; 90(1-3): 308-315. [PubMed: 17150337] 
Shenton ME, Kikinis R, Jolesz FA, Pollak SD, LeMay M, Wible CG, Hokama H, Martin J, Metcalf D, Coleman M, et al. Abnormalities of the left temporal lobe and thought disorder in schizophrenia. A quantitative magnetic resonance imaging study. The New England journal of medicine. 1992; 327(9):604-612.

Shergill SS, Brammer MJ, Williams SC, Murray RM, McGuire PK. Mapping auditory hallucinations in schizophrenia using functional magnetic resonance imaging. Archives of general psychiatry. 2000; 57(11):1033-1038. [PubMed: 11074868]

Song SK, Sun SW, Ju WK, Lin SJ, Cross AH, Neufeld AH. Diffusion tensor imaging detects and differentiates axon and myelin degeneration in mouse optic nerve after retinal ischemia. NeuroImage. 2003; 20(3):1714-1722. [PubMed: 14642481]

Song SK, Sun SW, Ramsbottom MJ, Chang C, Russell J, Cross AH. Dysmyelination revealed through MRI as increased radial (but unchanged axial) diffusion of water. NeuroImage. 2002; 17(3):1429_ 1436. [PubMed: 12414282]

Song SK, Yoshino J, Le TQ, Lin SJ, Sun SW, Cross AH, Armstrong RC. Demyelination increases radial diffusivity in corpus callosum of mouse brain. NeuroImage. 2005; 26(1):132-140. [PubMed: 15862213]

Stephan KE, Friston KJ, Frith CD. Dysconnection in schizophrenia: from abnormal synaptic plasticity to failures of self-monitoring. Schizophrenia bulletin. 2009; 35(3):509-527. [PubMed: 19155345]

Stevens B, Tanner S, Fields RD. Control of myelination by specific patterns of neural impulses. J Neurosci. 1998; 18(22):9303-9311. [PubMed: 9801369]

Sturm W, Willmes K. On the functional neuroanatomy of intrinsic and phasic alertness. NeuroImage. 2001; 14(1 Pt 2):S76-84. [PubMed: 11373136]

Takeuchi H, Sekiguchi A, Taki Y, Yokoyama S, Yomogida Y, Komuro N, Yamanouchi T, Suzuki S, Kawashima R. Training of working memory impacts structural connectivity. J Neurosci. 2010; 30(9):3297-3303. [PubMed: 20203189]

Tkachev D, Mimmack ML, Ryan MM, Wayland M, Freeman T, Jones PB, Starkey M, Webster MJ, Yolken RH, Bahn S. Oligodendrocyte dysfunction in schizophrenia and bipolar disorder. Lancet. 2003; 362(9386):798-805. [PubMed: 13678875]

Wang Y, Fernandez-Miranda JC, Verstynen T, Pathak S, Schneider W, Yeh FC. Rethinking the Role of the Middle Longitudinal Fascicle in Language and Auditory Pathways. Cerebral cortex. 2012

Whitford TJ, Grieve SM, Farrow TF, Gomes L, Brennan J, Harris AW, Gordon E, Williams LM. Progressive grey matter atrophy over the first 2-3 years of illness in first-episode schizophrenia: a tensor-based morphometry study. NeuroImage. 2006; 32(2):511-519. [PubMed: 16677830]

Whitford TJ, Kubicki M, Schneiderman JS, O'Donnell LJ, King R, Alvarado JL, Khan U, Markant D, Nestor PG, Niznikiewicz M, McCarley RW, Westin CF, Shenton ME. Corpus Callosum Abnormalities and Their Association with Psychotic Symptoms in Patients with Schizophrenia. Biological psychiatry. 2010

Wible CG, Kubicki M, Yoo SS, Kacher DF, Salisbury DF, Anderson MC, Shenton ME, Hirayasu Y, Kikinis R, Jolesz FA, McCarley RW. A functional magnetic resonance imaging study of auditory mismatch in schizophrenia. The American journal of psychiatry. 2001; 158(6):938-943. [PubMed: 11384903]

Wible CG, Lee K, Molina I, Hashimoto R, Preus AP, Roach BJ, Ford JM, Mathalon DH, McCarthey G, Turner JA, Potkin SG, O'Leary D, Belger A, Diaz M, Voyvodic J, Brown GG, Notestine R, Greve D, Lauriello J. fMRI activity correlated with auditory hallucinations during performance of a working memory task: data from the FBIRN consortium study. Schizophrenia bulletin. 2009a; 35(1):47-57. [PubMed: 18990710]

Wible CG, Preus AP, Hashimoto R. A Cognitive Neuroscience View of Schizophrenic Symptoms: Abnormal Activation of a System for Social Perception and Communication. Brain imaging and behavior. 2009b; 3(1):85-110. [PubMed: 19809534]

Wilkinson, GS. Wide Range Achievement Test-3 (WRAT-3). Lutz, FL: 1993.

Wilson SM, Molnar-Szakacs I, Iacoboni M. Beyond superior temporal cortex: intersubject correlations in narrative speech comprehension. Cereb Cortex. 2008; 18(1):230-242. [PubMed: 17504783] 

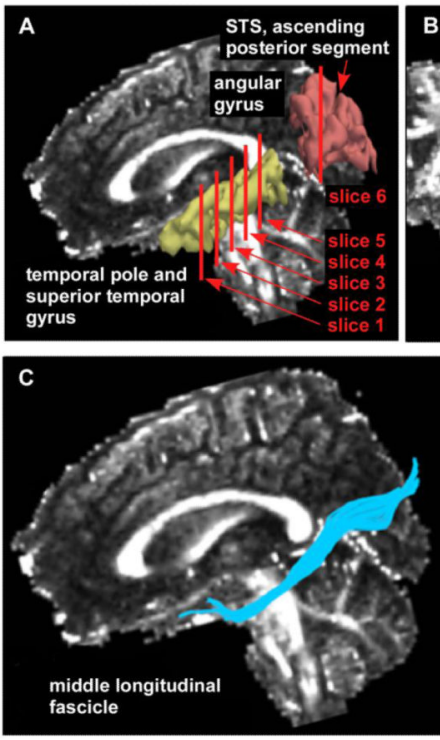
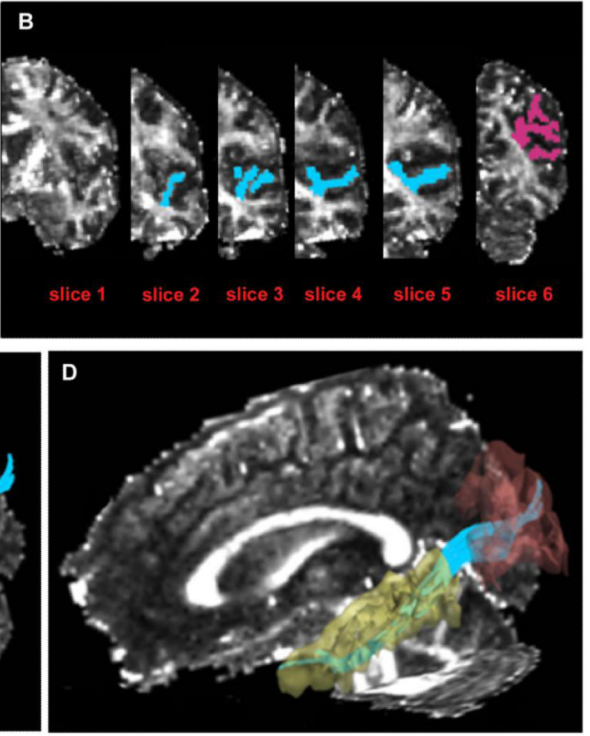

Figure1.

Abbreviation: STS, superior temporal sulcus, Region of interests (ROIs) used to extract the middle longitudinal fascicle (blue: 4 ROIs in superior temporal gyrus, pink: 1 ROI in angular gyrus) (Figure1-A and B). Figure1-C and D show anatomical relationships between middle longitudinal fascicle (blue) and temporal pole, superior temporal gyrus (yellow), and angular gyrus (brown). 

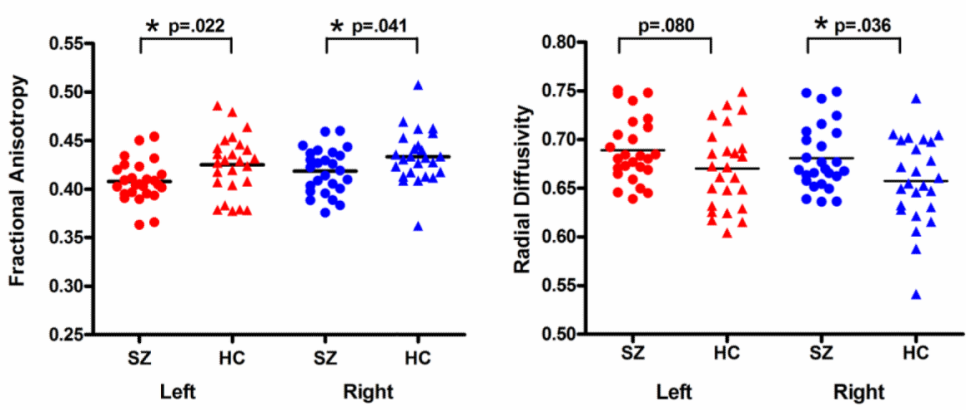

Figure2.

Results of group comparisons in Fractional Anisotropy and Radial Diffusivity. Abbreviations: SZ, schizophrenia; HC, healthy control. * $\mathrm{P}<.05$. 

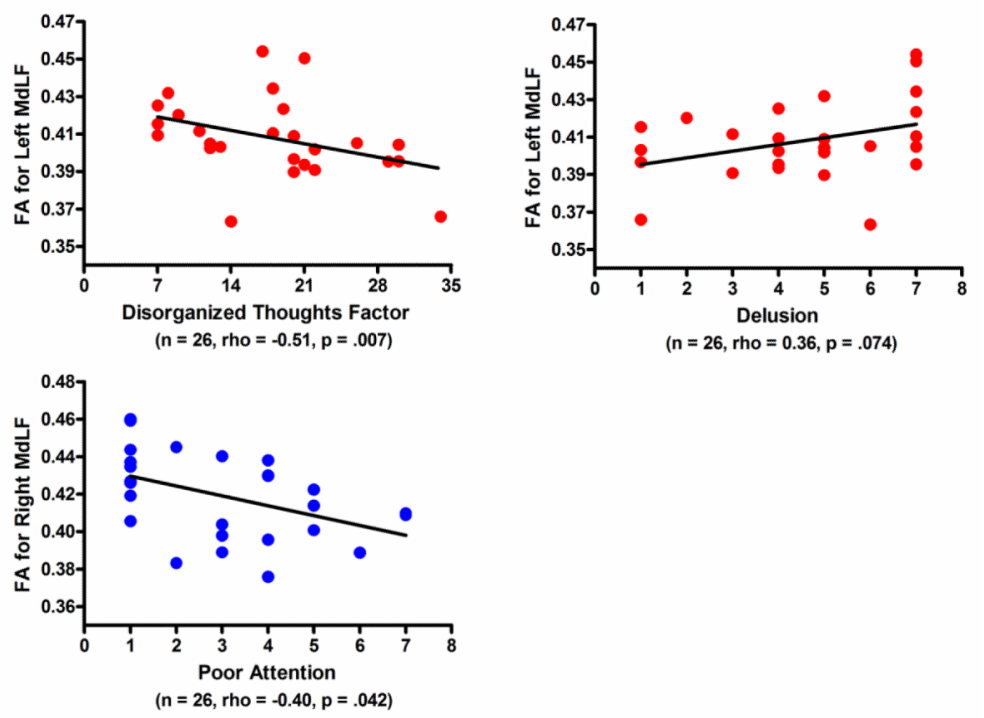

Figure3.

Scatter grams for fractional anisotropy (FA) of middle longitudinal fascicle (MdLF) and clinical symptoms in the patients with chronic schizophrenia. 


\section{Table 1}

Demographic and clinical characteristics of the study groups

\begin{tabular}{|c|c|c|c|c|c|c|c|}
\hline \multirow[b]{2}{*}{ Variable } & \multicolumn{2}{|c|}{$\underset{(n=26)}{S Z \text { group }}$} & \multicolumn{2}{|c|}{$\underset{(n=25)}{H C \text { group }}$} & \multirow[b]{2}{*}{$d f^{a}$} & \multirow[b]{2}{*}{$\stackrel{t}{t}$} & \multirow[b]{2}{*}{$P$} \\
\hline & Mean (SD) & $\mathbf{n}$ & Mean (SD) & $\mathbf{n}$ & & & \\
\hline Age, mean (SD) [range], years & $\begin{array}{l}40.8(10.4) \\
{[20-55]}\end{array}$ & {$[\mathrm{n}=26]$} & $\begin{array}{l}40.4(10.0) \\
{[22-55]}\end{array}$ & {$[\mathrm{n}=25]$} & 49 & 0.17 & .87 \\
\hline Sex, No. M/F & $26 / 0$ & {$[n=26]$} & $25 / 0$ & {$[\mathrm{n}=25]$} & & & \\
\hline Handedness $b$ & $0.73(0.25)$ & {$[\mathrm{n}=26]$} & $0.76(0.21)$ & {$[\mathrm{n}=25]$} & 49 & 0.57 & .57 \\
\hline Education, years & $13.2(1.8)$ & {$[\mathrm{n}=26]$} & $15.1(1.9)$ & {$[\mathrm{n}=25]$} & 48 & 3.51 & $.001^{*}$ \\
\hline \multicolumn{8}{|l|}{ Socioeconomic Status $c$} \\
\hline Subject's & $3.4(1.1)$ & {$[n=26]$} & $2.0(0.7)$ & {$[\mathrm{n}=25]$} & 49 & 5.69 & $<.001^{*}$ \\
\hline Parental & $2.2(1.0)$ & {$[\mathrm{n}=24]$} & $2.6(1.1)$ & {$[\mathrm{n}=24]$} & 47 & 1.41 & .17 \\
\hline WRAT-3: reading score & $97.8(12.5)$ & {$[\mathrm{n}=24]$} & $103.3(12.9)$ & {$[\mathrm{n}=25]$} & 46 & 1.50 & .14 \\
\hline Symptom onset, years & $23.7(5.1)$ & {$[n=26]$} & NA & & & & \\
\hline Duration of illness, years & $20.2(10.3)$ & {$[\mathrm{n}=26]$} & NA & & & & \\
\hline $\begin{array}{l}\text { Antipsychotic medication } \\
\text { dosage }(\mathrm{mg} / \text { day })^{d}\end{array}$ & $408.7(328.8)$ & {$[\mathrm{n}=26]$} & NA & & & & \\
\hline \multicolumn{8}{|l|}{ Neuroleptics, No. of patients } \\
\hline $\begin{array}{l}\text { TYP/ATYP/Overlap/Non- } \\
\text { medication }\end{array}$ & $2 / 18 / 4 / 2$ & {$[\mathrm{n}=26]$} & NA & & & & \\
\hline $\begin{array}{l}\text { Number with/without family } \\
\text { history of first-degree relatives } \\
\text { with psychosis }\end{array}$ & $3 / 23$ & {$[\mathrm{n}=26]$} & NA & & & & \\
\hline \multicolumn{8}{|l|}{ PANSS } \\
\hline Disorganized Thoughts Factor & $18.0(7.7)$ & {$[\mathrm{n}=26]$} & NA & & & & \\
\hline Poor Attention & $3.1(2.0)$ & {$[\mathrm{n}=26]$} & NA & & & & \\
\hline Positive Symptom Factor & $22.6(8.4)$ & {$[\mathrm{n}=26]$} & NA & & & & \\
\hline Delusion & $4.5(2.1)$ & {$[\mathrm{n}=26]$} & NA & & & & \\
\hline Hallucinatory Behavior & $4.5(2.1)$ & {$[n=26]$} & NA & & & & \\
\hline Negative Symptom Factor & $24.0(13.5)$ & {$[n=26]$} & NA & & & & \\
\hline
\end{tabular}

Abbreviations: SZ, schizophrenia; HC, healthy control subject; WRAT-3, Wide Range Achievement Test-3; TYP, typical antipsychotics; ATYP, atypical antipsychotics; Overlap, both typical and atypical antipsychotics; PANSS, the Positive and Negative Symptom Scale; NA, data not applicable

${ }^{*}<<.05$

$a_{\text {The }} d f s$ differ among variables because data from some participants were unavailable.

${ }^{b}$ Handedness was evaluated using the Edinburgh inventory, with right handedness being greater than 0 .

cHigher scores mean lower socioeconomic status.

${ }^{d}$ Chlorpromazine equivalent dosage at the scan 